\title{
Smart Devices' Contribution to the Development of Virtual Museology in Turkey
}

\author{
Burcu Kir Savaş \\ Dept. of Computer Engineering \\ Kocaeli University \\ Kocaeli, Turkey
}

\author{
Oktay Duman \\ Dept. of Computer Engineering \\ Kocaeli University \\ Kocaeli,Turkey
}

\author{
Suhap Şahin \\ Dept. of Computer Engineering \\ Kocaeli University \\ Kocaeli,Turkey
}

\begin{abstract}
In this paper, it is aimed to announce the events that may direct people to museums by using mobile application virtually, and to give the information to visitors about the pieces in the museum, the result of which is expected to increase the number of the visitors. Therefore, it is provided that the museums become places interacted with visitors by means of tablets and mobile devices. The paper is realized on mobile operating systems and communication process is provided with web services technology. Incoming event information, entered to the system by the museum management, is transferred to smart devices with polling services, namely to visitors. This forms a virtual social communication between the visitors and the museums.
\end{abstract}

\section{Keywords}

Mobile Operating Systems, Virtual Museology, Social Application, Polling Service, JSON.

\section{INTRODUCTION}

Today, mobile devices can be said to develop into ubiquitous devices in almost everyone's pocket considering the number of smart phones used around the world [1]. Mobile devices and the applications have been getting quite popular. Consequently, it is inevitable that these mobile applications are becoming parts of humans' lives. It emerges as a problem that the museums cannot announce the events, which may attract people attentions and lead them to those places, by using mobile application on virtual platform. Another problem is that visitors are not informed about the pieces dynamically.

There are many valuable pieces in the museums of Turkey. However, only a few are displayed properly. The information about these pieces is not visually and aurally presented very well. Some reasons are that the technologies in the museums are inadequate, which effects visitors' satisfaction in a negative way. On the other hand, major museums like Londra British Museum, New York Metropolitan Museum can attract people not only from their own countries but also from other countries [2]. Ceipidor, et all [3] present the design of a multimedia mobile guide for the visitors of the Wolfsoniana museum of Genoa. The system presented is part of an upcoming field trial aiming to research about Usability and User Experience (UX) of Near Field Communication (NFC) technology applied to the touristic-cultural field. Rudametkin et all [4] present an architecture for providing an augmented experience for exhibits. Angelaccio et all [5] deals with the design of an AmI-based Information Systems, based on NFC (Near Field Communication) technology, developed to access Cultural Heritage Areas of particular interest, in which different objects of artistic interest can be interfaced in a proper virtual way without affecting the historical environment. Fevgas, et all [6] virtual museum platform, named iMuse is presented in this paper. The platform aims to enhance museum visits, assist visitors navigate inside the museum and to provide access to multimedia content using the recent advances in Web, RFIDs and communication technologies. In more detail, the iMuse Virtual Museum is based on three components: Mobile Tour, Virtual Presenter and Virtual Wing.

The increase in the use of mobile devices makes the mobile devices more accessible [7]. It has become necessary to add devices like tablets and smart phones to assist the exhibition in the museums $[2,8]$. Positive effects in the use and the accessibility of mobile devices have been increasing day by day [7]. That is why mobile devices were preferred.

This paper aims to increase the number of the visitors, to transform the museums into more virtual environments with the help of tablets, to increase the interaction between the museums and the visitors, to be able to announce the events to the visitors online and to be able to update and cloud synchronize the new information about the pieces.

The rest of this paper is organized as follows: Section 2 mentions analysis of problem, Section 3 describes the methods used and software architectural structure, Section 4 mentions proposed system and Section 5 presents the conclusion and future works.

\section{ANALYSIS OF PROBLEM}

Considering the recent technological developments, it is regarded as necessary that mobile devices contribute to the display of pieces of art [9]. It is also seen that some museums in the world have adopted the latest developments on mobile devices [2,9]. Nonetheless, those systems which are using mobile technologies cause a huge amount of cost and workload. In addition, it is ethically unfavorable for security reasons to use foreign systems when it comes to national values.

Many museum applications focus on an interface that interacts between only user-museum $[10,11]$. Besides providing such interfaces, this work contributes to the use and the development of virtual museology in Turkey.

\section{METHODS USED AND SOFTWARE ARCHITECTURAL STRUCTURE}

In this section, information about the methods used in this study is given and the system architectural structure is shown.

\subsection{Web service}

Web services module can be connected remotely and accomplish certain tasks. Mobile device (client) can call certain web services from the server by using RPC (Remote Procedure Calling) [12]. The use of web services on mobile applications increases the flexibility of the applications, and 
decreases the workload of the CPU and provides services variety.

\subsection{JavaScript Object Notation}

JavaScript Object Notation (JSON) has a data format that is interchangeable with a programming languages built-in data structures that eliminates translation time and reduces complexity and processing time [13, 14]. JSON is more advantageous compared to XML as it is a lightweight datainterchange format easy for humans to read and write and easy for machines to parse and generate to XML [13]. For this reason, it was preferred that the data was taken in JSON format from web service. This data includes the media to be played on the tablets, its duration information, and sleep time of those tablets.

\subsection{Polling service}

Polling services uses the "Query with the specific time ranges" while obtaining data from data sources. Configuration is described on outer systems by an operating service. This occurs with data gathering when outer systems are accessed periodically [15]. There are two different uses for Real Time Polling Service and Non-Real Time Polling Service.

The communication process is provided with web service technology. The incoming information about the events is transferred the smart devices via Polling Service. Thanks to this study, the information and announcements about the events entered by the administration of museums are relayed to the visitors on mobil devices. Architecture of the system is shown in Fig. 1 and in Fig. 2 architectural structure is demonstrated.

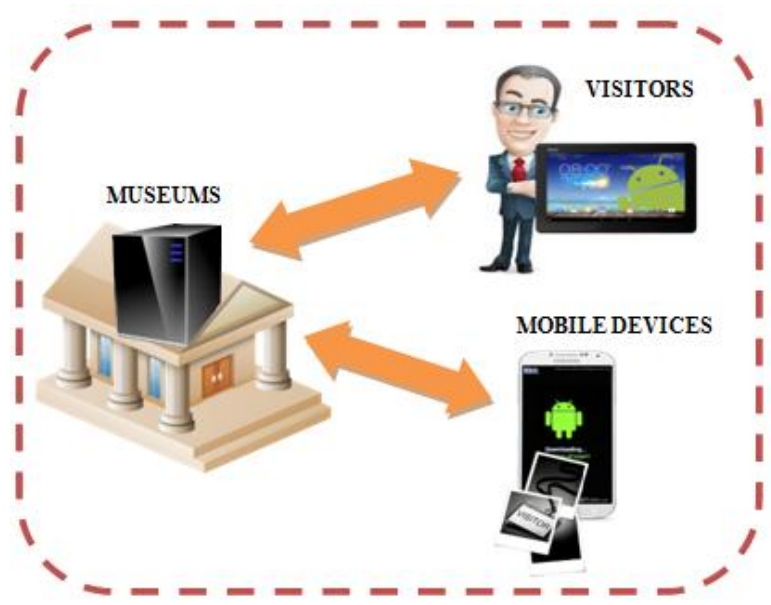

Fig 1: Architecture of the System

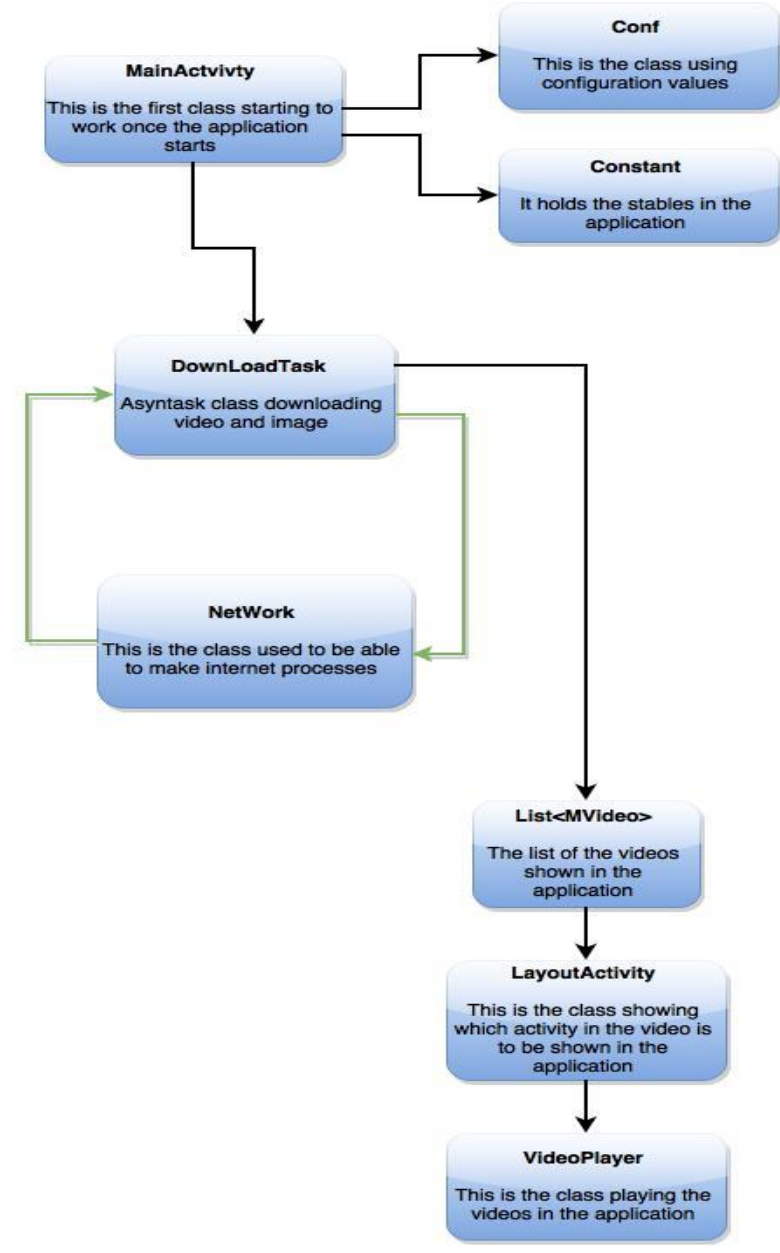

Fig 2: Architectural Structure

\section{PROPOSED SYSTEMS}

This section explains how the methods mentioned in section 3 are used and how system architecture structure works.

In the work, content management is provided via tablets. This way, content management is realized effectively. Additionally, on local servers, contents in tablets in one museum, which carry the information about the duration of the visual media, can be managed. Linux operating system is used as for the local server side of the work, while as for the client side Android operating system is used as a beginning. The management part is on the local server. Tablets and smart phones are used as clients. The web service between the client and the local server provides the communication with JSON data structure. It is provided receiving data from the external systems (local servers) with polling service. Synchronization is made between the clients in the museums and the local server in any central point. This way, interactive use of the museums is provided through $1-1,1-\mathrm{N}, \mathrm{N}-\mathrm{N}$ ports. In this work, synchronization is realized between client-client and client-server. Media to be used in the tablets will be entered by the museum personnel. Media data to be presented to the clients will be sent to the client chosen by the application.

Media is cached on clients to use the internet sources efficiently. Thus, it is aimed to prevent from that the same data is sent constantly and traffic intensity occurs on the local server side. Tablets' plans will be transferred to the client smart phones with JSON data structure. The data received by 
the device is automatically saved on the device's memory and operates according to that plan during the day. Also, in case of any situation when the internet is off, related plan is saved on hard disks in the museum, so devices will follow the last saved plan in case of internet outage.

For a list of the designed functions see Table 1.

Table 1. Main required functions of the mobile application

\begin{tabular}{|c|c|}
\hline $\begin{array}{c}\text { clickStart } \\
\text { (View v) }\end{array}$ & $\begin{array}{c}\text { links to "all museums", "museums visited } \\
\text { before" and "current museums" }\end{array}$ \\
\hline $\begin{array}{c}\text { parsJson } \\
\text { (JSON Object } \\
\text { object) }\end{array}$ & $\begin{array}{c}\text { converts the JSON object from the service } \\
\text { into the parse list and makes it possible to } \\
\text { see the list of all museums. }\end{array}$ \\
\hline $\begin{array}{c}\text { onQRCode } \\
\text { Read }\end{array}$ & $\begin{array}{c}\text { provides QR code reading to find out which } \\
\text { museum the visitor is in and detailed } \\
\text { information about it. }\end{array}$ \\
\hline getData & $\begin{array}{c}\text { shows the user the media, the list of pieces, } \\
\text { and the information about the museum } \\
\text { coming from the server after QR code } \\
\text { query. }\end{array}$ \\
\hline
\end{tabular}

In Fig. 3, shows software user interface of the system in the work. System user interface consist of three parts. Part X, shown in red and named "Tüm Müzeler" shows the list of all the museums of the cities in Turkey. This way, it is easier to find the city being searched and the museums in it, as well. After the search all the information about the museum and the pieces can be reached. Users can easily reach the pieces and the information (text, picture and video) about them on interface. In part Y, shown in orange and named "Geçmiş", users can find the museums visited before and information about pieces looked for before. In part Z, shown in purple and named "Şimdiki", the visitors can reach the information about the museums/pieces/events by connecting to the local server via tablets and mobile devices.

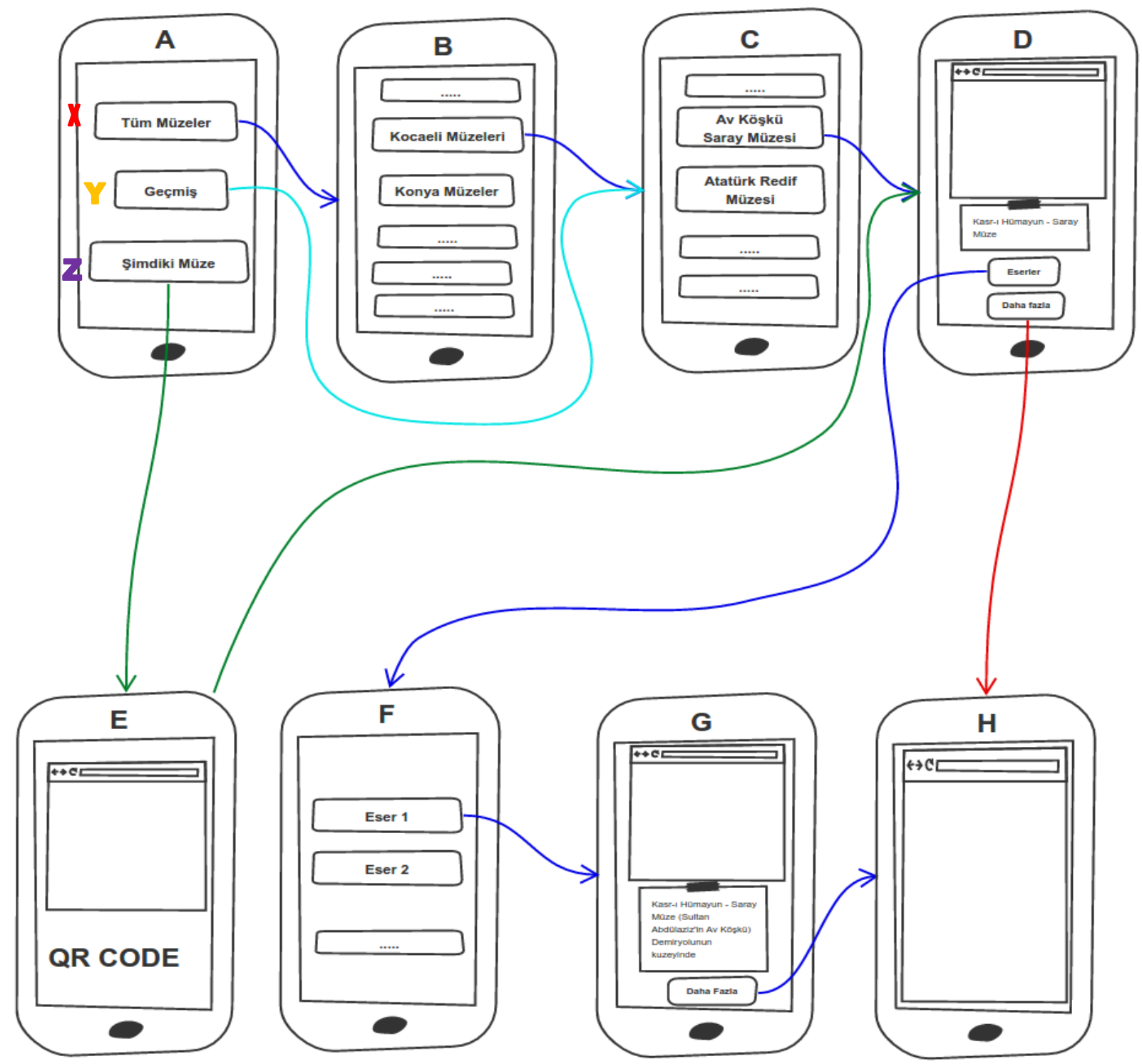

Fig 3: Software user interface of the system 


\section{CONCLUSION AND FUTURE WORKS}

This work aims to increase the number of native and foreign visitors visiting Turkey's museums. In addition, it is provided that the museums will be interactive places with the visitors by means of tablets and mobile devices. Updates on local server and the announcement of events information entered on the local server are realized by not making clients busy. Synchronisation is made between clients in one/more than one museum and a central server at any point and/or between two clients (tablet/smartphone). This work is supported by TÜBİTAK (The Scientific and Technological Research Council of Turkey) under 1005 - National New Ideas and Products R\&D Funding Program.

Future work will be focused on producing $\mathrm{QR}$ codes to enhance searching the pieces on tablets and smartphones and on developing algorithms relating those codes with the pieces. It will be realized that the events will be transferred realtimely from a central cloud server to local servers or clients.

\section{REFERENCES}

[1] Leonard, H. 2013. 1.5 Billion Smartphones In The World - Business Insider. http://www.businessinsider.com/15-billion-smartphonesin-the-world-22013-2. (Access date: 13.07.2015).

[2] Ceipidor, U., Medaglia, C. M., Volpi, V., Moroni A., Sposato, S., Carboni, M., Caridi, A. 2013. NFC technology applied to touristic-cultural field: a case study on an Italian museum. Near Field Communication 5th International Workshop on.

[3] Rudametkin, W., Gama, K., Touseau, L., Donsez, D. 2010. Towards a dynamic and extensible middleware for enhancing exhibits. 7th IEEE Consumer Communications and Networking Conf. (CCNC).

[4] Angelaccio, M., Basili, A., Buttarazzi, B., Liguori, W. 2012. Smart and mobile access to cultural heritage resources: a case study on ancient Italian renaissance villas. IEEE 21st Int. Workshop on Enabling Technologies: Infrastructure for Collaborative Enterprises (WETICE).

[5] Fevgas, A., Fraggogiannis N., Tsompanopoulou, P., Bozanis, P. 2014. The iMuse virtual museum: towards a cultural education platform. The 5th International
Conference on Information, Intelligence, Systems and Applications (IISA).

[6] Abd El-Aziz, A. A., Kannan, A. 2014. JSON encryption. International Conference on Computer Communication and Informatics (ICCCI).

[7] Fredlund L. A., Herranz, A., Earle, C. B., Marino, J. 2014. Property-based testing of JSON based web services. 2014 IEEE International Conference on Web Services.

[8] T. Wongsattho, L. Kovavisaruch, T. Sanpachuda, K.Chinda, S. Wisadsud, A. Chaiwongyen, "The development of museums network guide system by using QR code on smart phone", WMS Journal of Management, 2015, in press.

[9] Kovavisaruch, L., Sanpachuda, T., Chinda, K., Wongsattho, T., Chaiwongyen, A., Wisadsud, S., 2015. Museums pool: a mobile application for museum network. 2015 Proceedings of Picmet!'15: Management of the Technology Age.

[10] V. Keleş, "Modern müzecilik ve Türk müzeciliği”, Atatürk Üniversitesi Sosyal Bilimler Enstitüsü Dergisi, 2003 , in press.

[11] Ş. Karaca, M. Gülmez, "Mobil pazarlama: kavramsal bir değerlendirme", Journal Of Academic Approaches, 2010, in press.

[12] Çolak, C. 2006. Sanal müzeler. XI. "Türkiye'de İnternet" Konferans1 Bildirileri (inet-tr'06).

[13] A. Dolunay, B. Boyraz, "Dijital sanatlar çerçevesinde üretilen eserlerde teknoloji kullanımı ve internetin sergilemeye etkisi", Journal of the Human and Social Science Researches, 2013, in press.

[14] Toprak, Ö. and Altunbay, S. 2002. Java ve SOAP kullanılarak mobil cihazlardan hisse senedi alımı uygulamas1. Türkiye İnternet Konferans1 (VIII Inetrí02).

[15] Cengiz, A, Gündüz, K, Ünverdi, N. Ö. 2009. WiMAX teknolojisinde performans analizi. Elektrik-ElektronikBilgisayar ve Biyomedikal Mühendisliği 13. Ulusal Kongresi Ve Fuari. 